\title{
COMPOSIÇÃO CENTESIMAL E TEOR DE COLESTEROL DOS CORTES COMERCIAIS DE CAPIVARA (Hydrochaeris hydrochaeris L. 1766)
}

\author{
Centesimal composition and cholesterol content in \\ commercial cuts of capybaras (Hydrochaeris hydrochaeris L. 1766)
}

\author{
Sandra H. I. Oda ${ }^{1}$, Maria Cristina Bressan ${ }^{1}$, Rilke Tadeu Fonseca de Freitas ${ }^{3}$, \\ Giulianna Z. Miguel ${ }^{1}$, Josye O. Vieira ${ }^{2}$, Peter B. Faria ${ }^{2}$, Taciana V. Savian ${ }^{3}$
}

\begin{abstract}
RESUMO
Com o presente trabalho, objetivou-se determinar a composição centesimal e o teor de colesterol presente dos diferentes cortes comerciais da carne de capivara. A umidade, proteína, extrato etéreo e cinzas foram determinados segundo a AOAC (1990). O colesterol foi determinado por colorimetria. Os cortes comerciais apresentaram média de 75,80\% de umidade; 21,74\% de proteína; 0,74\% de lipídios; 0,90\% de cinzas; e 23,3 mg/100g de colesterol. Houve diferença $(\mathrm{P}<0,05)$ nos percentuais de umidade e colesterol entre os cortes comerciais; entretanto, não houve diferença sobre os teores de proteína, lipídios e cinzas. Pelos resultados encontrados, verificase um baixo teor de lipídios totais e de colesterol, quando comparados com os valores apresentados para carnes de outras espécies.
\end{abstract}

Termos para indexação: Capivara, cortes, proteina, lipídeos, colesterol.

\section{ABSTRACT}

The aim of this work was to determine the proximate composition and cholesterol content in different commercial cuts of capybara. Moisture, crude fat, lipids and ash were determined following AOAC (1990) methods. Cholesterol content was determined by colorimetric method. Commercial cuts had values of: $75.8 \%$ of moisture; $21.74 \%$ of crude protein; $0.74 \%$ of crude fat; $0.90 \%$ of ash and $23.3 \mathrm{mg} / 100 \mathrm{~g}$ of cholesterol. There were significant $(\mathrm{P}<.05)$ differences on percentages of moisture and cholesterol content in the different commercial cuts. However, there was no difference on crude protein, crude fat and ash values. Results showed a lower percentage of lipids and cholesterol content in comparison with the meat of other species.

Index terms: Capybara, cuts, protein, fat, cholesterol.

(Recebido para publicação em 6 de agosto de 2002 e aprovado em 8 de outubro de 2004)

\section{INTRODUÇÃO}

A utilização racional ou sustentável da fauna silvestre é um processo benéfico que pode resultar em vantagens econômicas, sociais e, ao mesmo tempo, proteger as espécies silvestres da extinção (OJASTI, 1973; ALHO, 1986; HERRERA, 1999). Os fatores responsáveis pela redução da fauna são: a) a caça de subsistência, que apesar de sua grande importância na sobrevivência de populações ribeirinhas e tribos indígenas, tende a conduzir ao extermínio de espécies; b) a caça comercial, em que a matança de animais ocorre de acordo com a exigência do mercado (carne, pele ou couro, plumas ou, ainda, animais vivos); e, c) a destruição dos habitats para dar lugar à exploração agropecuária (BERLIN e BERLIN, 1978; GAVIRIA, 1980).

O êxito no manejo de fauna silvestre é baseado no conhecimento do comportamento da espécie com relação a padrões do uso do habitat e obtenção de alimentos, hábitos reprodutivos e predadores, de forma a contemplar a dinâmica de populações (OJASTI, 1973).

A fauna de mamíferos, com sua diversidade de espécies, embora seja susceptível à perturbação, é viável para a utilização econômica, mas requer um plano de manejo e criação (ALHO, 1986). Entre as propostas de utilização da fauna silvestre de forma racional, estão: a criação dos animais em cativeiro, a implantação da caça esportiva em fazendas com criatórios de animais silvestres, a implementação de um plano de manejo extensivo, o turismo ecológico, a exploração integrada de animais silvestres com o gado e o aproveitamento de terrenos marginais. Os animais silvestres podem se transformar em fontes renováveis de produtos de grande rentabilidade, contribuindo para a produção de alimentos e concorrendo, em custo de produção, com os animais domésticos. Considerando essas premissas, o IBAMA (1997) homologou a portaria número 118 (15 de outubro de 1997), que normaliza o funcionamento de criadouros de animais da fauna silvestre brasileira com fins econômicos e industriais.

1. Departamento de Ciência dos Alimentos, Universidade Federal de Lavras/UFLA, Caixa Postal 3037 - 37200-000 - Lavras, MG.

2. Departamento de Medicina Veterinária, UFLA.

3. Departamento de Zootecnia, UFLA. 
Os animais silvestres produzem carne com teores reduzidos de lipídeos totais e colesterol, além de apresentarem altas proporções de ácidos graxos poliinsaturados, quando comparados aos animais domésticos (CRAWFORD et al., 1976; SINCLAIR et al., 1982; NAUGHTON et al., 1986; SINCLAIR e O'DEA, 1990). Com relação a lipídios totais em capivaras, Jardim et al. (2003) descreveram no músculo longissimus dorsi médias de 0,82 g/100g; Saldanha (2000) descreveu em pernil e paleta média de 0,91 g/100g e Roça et al. (1996) relataram em copa (músculos cervicais) valores de 1,6 $\mathrm{g} / 100 \mathrm{~g}$. Esses aspectos nutricionais observados em animais silvestres são desejáveis quando se considera que o conjunto de atitudes do homem moderno em relação aos hábitos de vida, tais como vida sedentária, estresse e ingestão elevada de alimentos ricos em gorduras, é associado a quadros de obesidade, hipertensão, hipercolesterolemia e problemas cardiocirculatórios. Além disso, os profissionais da área de saúde relacionam a elevada incidência de enfermidades cardiocirculatórias ao consumo de carne vermelha (WOOD, 1990). Essa posição tem sido adotada nas últimas décadas, ocasionando uma redução na ingestão de carne, um importante componente da dieta, que fornece aminoácidos e ácidos graxos essenciais, vitaminas e sais minerais (FORREST et al., 1979; PARDI et al., 1993).

A capivara, maior roedor do planeta, tem hábitos semi-aquáticos e ampla distribuição pela América do Sul. Ocupa os mais diferentes habitats, desde matas ciliares a savanas sazonalmente inundáveis e manguezais salobros, chegando a altitudes de até $1.500 \mathrm{~m}$. As maiores densidades dessa espécie são encontradas no Pantanal Matogrossense, vale do Amazonas e savanas úmidas da Venezuela (MOREIRA et al., 1997). A criação comercial dessa espécie tem atraído a atenção de proprietários rurais, em razão do baixo custo de produção (herbívoro monogástrico) e da possibilidade de exploração econômica de áreas de formações ciliares (cuja preservação é obrigatória segundo Decreto ${ }^{\circ} 3.420$, de 20 de abril de 2000, cujo objetivo geral é "a promoção do desenvolvimento sustentável, conciliando a exploração com a proteção dos ecossistemas e a compatibilização da política florestal com os demais setores de modo a promover a ampliação do mercado interno e externo e o desenvolvimento institucional do setor") (BRASIL, 2000). Assim, a capivara surge como uma espécie de mamífero sul-americano com grande potencial zootécnico.

Atualmente, o mercado consumidor de carne tem se mostrado bastante receptivo ao consumo de carne de animais silvestres e exóticos. Apesar da existência de uma demanda pela carne de capivara nos grandes centros e da possibilidade de abertura de novos mercados (mercado externo), os estudos da composição química da carne de capivara e aspectos nutricionais são escassos e trabalhos que caracterizam a composição dos possíveis cortes comerciais são restritos.

Objetivou-se com o presente trabalho determinar a composição centesimal e o teor de colesterol nos diferentes cortes comerciais da carne de capivaras.

\section{MATERIAL E MÉTODOS}

Neste trabalho, foram utilizados cinco animais adultos com com peso vivo médio de 63,8 kg, machos e fêmeas, provenientes de cativeiro (baias individuais), alimentados com forragens (napier) e ração à base de milho e farelo de soja, com $15 \%$ de proteína bruta e $3375 \mathrm{kcal} / \mathrm{kg}$ de energia digerível, formulada de acordo com as exigências nutricionais recomendadas para suínos em terminação (ROSTAGNO et al., 2000).

As capivaras, no pré-abate, permaneceram recebendo alimentação e não foram transportadas ou deslocadas vivas das baias (a fim de evitar situações de estresse). $\mathrm{O}$ abate foi realizado por tiro na região têmporo-ocipital e, após essa medida, procederam-se às seguintes etapas: a) sangria por secção das artérias carótidas e veias jugulares; b) retirada dos pêlos por queima, seguida de lavagem e raspagem externa; c) evisceração; d) divisão da carcaça em meias-carcaças (no sentido longitudinal), com a retirada da cabeça e patas; e e) resfriamento das meias-carcaças a $5^{\circ} \mathrm{C}$ por 24 horas.

A meia-carcaça foi separada em cortes, conforme proposta descrita por Santos (1999) para ovinos, em cinco regiões anatômicas denominadas: pernil, paleta, peito/fralda (costela/fralda), carré (costeleta), lombo e pescoço, conforme descrito a seguir e mostrado na Figura 1:

Paleta - as regiões anatômicas que compreenderam esse corte foram o cíngulo escapular, braço e antebraço. A base óssea foi formada pela escápula, úmero, rádio e ossos do carpo. O corte foi obtido mediante secção da região axilar e dos músculos que unem a escápula e o úmero na parte ventral do tórax. Em seguida, foi contornada a escápula, seccionando os músculos braquiocefálico, omo transversal, trapézio cervical e serrato cervical, pela parte superior, e trapézio torácico e rombóides pela parte posterior do tronco; 
Pernil (perna) - compreendeu a região sacral e os seguintes segmentos anatômicos do membro pélvico: cíngulo pélvico e perna. A base óssea foi formada pelo tarso, tíbia, fêmur, ísquio, púbis e íleo. O corte foi obtido pela secção na região da articulação da última vértebra lombar e primeira sacral e na região da posição inicial dos ossos do tarso;

Lombo - a base óssea desse corte compreendeu da primeira à última vértebra lombar (seis ou sete vértebras). Para obtenção do corte, foi realizada, inicialmente, a secção entre a última vértebra torácica e primeira lombar, seguido de uma outra secção entre a última lombar e a primeira sacral;

Carré (costeleta) - compreendeu a região localizada entre a $1^{\mathrm{a}}$ e a $13^{\mathrm{a}}$ vértebra torácica, junto com aproximadamente $1 / 3$ dorsal do corpo das costelas correspondentes; e

Peito/fralda (costela/fralda) - este corte compreendeu a região anatômica da parede abdominal e 2/3 da região ventral torácica. Sua base óssea foi metade correspondente do esterno cortado sagitalmente, aproximadamente $2 / 3$ ventrais das oito primeiras costelas e terço ventral das cinco restantes.

Os cortes, após a desossa, foram acondicionados em sacos de polietileno e mantidos em freezer a $-12^{\circ} \mathrm{C}$. Desses cortes, os músculos foram dissecados (sem a gordura subcutânea e o tecido conectivo visível) e homogeneizados. Amostras de 50 gramas foram separadas, identificadas, congeladas a $-20^{\circ} \mathrm{C}$ e, para proceder às análises, as amostras foram descongeladas a $4^{\circ} \mathrm{C}$.
A proteína bruta foi quantificada pelo método de Kjeldahl, a umidade em estufa a $105^{\circ} \mathrm{C}$, os lipídeos totais foram extraídos segundo Soxhlet e as cinzas em mufla a $550^{\circ} \mathrm{C}$ (AOAC, 1990), em triplicatas. Os lipídeos foram extraídos com clorofórmio/metanol (FOLCH et al., 1957) e o teor de colesterol foi determinado de acordo com Bohac et al. (1988), adaptado por Bragagnolo e Rodriguez-Amaya (1995), para análise de colesterol por colorimetria.

O delineamento experimental foi em blocos casualizados, sendo considerado bloco o animal, com cinco tratamentos (cinco diferentes cortes comerciais) e cinco repetições, sendo o animal a unidade experimental. Para as análises dos dados obtidos, foi utilizado o pacote computacional Sisvar (FERREIRA, 2000) e o modelo estatístico seguido foi:

$$
Y_{i j}=\mu+C_{i}+A_{j}+e_{i j} \text {, em que }
$$

$\mathrm{Y}_{\mathrm{ij}}=$ observação do corte comercial $\mathrm{i}$, no animal j;

$\mu=$ é a constante associada a todas as observações; $\mathrm{C}_{\mathrm{i}}=$ efeito dos cortes comerciais $\mathrm{i}$, sendo $\mathrm{i}=1$, 2, 3, 4 e 5;

$A_{j}=$ efeito do animal $j$ (bloco), para $j=1$, 2, 3, 4 e 5;

$\mathrm{e}_{\mathrm{ij}}=$ é o erro experimental associado à observação $Y_{\mathrm{ij}}$, que, por hipótese, tem distribuição normal independentente distribuído com média zero e variância $\sigma^{2}$.

Quando a análise de variância identificou diferença significativa entre os cortes para cada variável analisada, as medias foram submetidas ao teste de Scott e Knott (1994) ao nível de probabilidade inferior a 5\% $(\mathrm{P}<0,05)$.

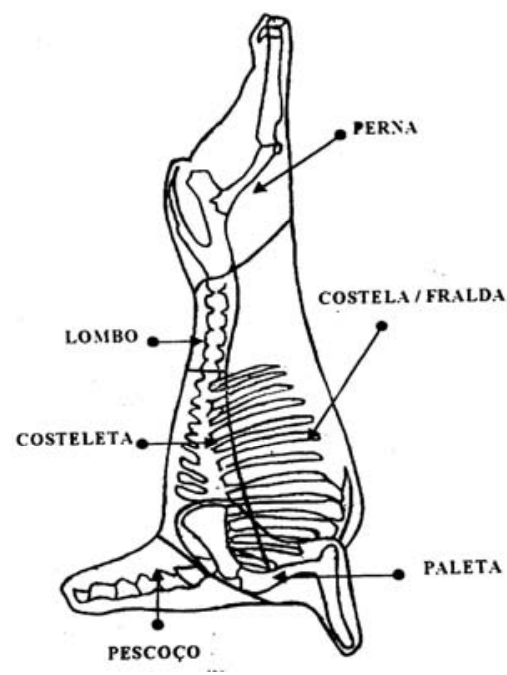

FIGURA 1 - Cortes realizados na 1⁄2 carcaça esquerda. 


\section{RESULTADOS E DISCUSSÃO}

Na análise de variância, não se revelaram diferenças entre os cortes para lipídeos totais, proteína e cinzas. Entretanto, houve diferença $(\mathrm{P}<0,05)$ entre os cortes para médias de umidade e colesterol (Tabela 1).

Os cortes lombo e carré (75,09 e 75,07 g/100g, respectivamente) apresentaram menor teor de umidade do que os cortes peito/fralda e pernil (76,05 e 75,84 g/100 g, respectivamente), os quais, por sua vez, foram inferiores à umidade encontrada na paleta (76,98 g/100 g). Comparando os cortes pernil e paleta de capivaras, Saldanha (2000) encontrou médias de 76,41\% e 77,29\%, respectivamente, que foram semelhantes, embora o corte paleta tenha apresentado maior percentual de água do que o pernil. Em camelo, Dawood e Alkanhal (1995) encontraram em costela e pernil médias de umidade de 69,55 e 74,57\%, respectivamente, que diferiram significativamente. Bragagnolo e Rodrigues-Amaya (1995) não observaram diferença para umidade entre os cortes de suínos (lombo e pernil com variação de 70 a 75\%) e corte de bovino (contrafilé, coxão duro, coxão mole e peito, com variação de 63 a $74 \%)$.

A média geral para proteína foi de 21,98 g/100 g. Esse dado foi superior à média descrita em capivaras por Saldanha (2000), em pernil e paleta (20,49 g/100 g); por Roça et al. (1996), em copa (20,04 g/100 g); e por Jardim (2001), no músculo longissimus dorsi (21,17 g/100 g), e foi semelhante à média descrita por Gaona (1987) de 22,1 g/100 g. Comparando com outras espécies, a quantidade de proteína encontrada em lombo (22,62 g/100 g) no presente trabalho foi superior à média encontrada em lombo de caprinos $(20,41 \mathrm{~g} / 100 \mathrm{~g})$ por Tarley et al. (1999). A proteína encontrada em pernil (22,45 g/100 g) nesse trabalho também foi superior às médias encontradas nos músculos bíceps femoris de ovinos (com peso de abate de 15 e $45 \mathrm{~kg}$ ), com médias de 20,3 a 21,4 g/100 g, respectivamente (BONAGURIO, 2001).

A média geral de lipídeos foi de 0,85 g/100 g. Resultados semelhantes em capivaras foram descritos por Jardim et al. (2003) no músculo Longissimus dorsi, com média de 0,82 g/100 g, e por Roça et al. (1996), em copa, com média de 0,91 g/100 g. Entretanto, Saldanha (2000) descreveu valores mais elevados de lipídeos nos cortes pernil e paleta, com média de 1,6 g/100 g. Em espécies convencionais, são descritas médias de lipídeos mais elevados. Bragagnolo (1997) citou média de 2,5 g/100 g em contrafilé de bovinos (Nelore) e média de $3 \mathrm{~g} / 100 \mathrm{~g}$ em lombo suíno. Em ovinos, Souza (2001) encontrou, no bíceps femoris, médias de 1,48, 2,07, 3,14 e 3,79 g/100 g, em animais de 15, 25, 35 e $45 \mathrm{~kg}$, respectivamente; e Bonagurio (2001) descreveu valores entre 1 e 3,5 g/100 g no mesmo músculo em animais de 15 a 45 kg. Vários fatores influenciam o percentual de gordura na carne, tais como sexo (FORREST et al., 1979; PARDI et al., 1993; SOUZA, 2001; JARDIM et al., 2003); idade de abate e grupamento genético (BONAGURIO, 2001; SOUZA et al., 2002 ). Entretanto, independente desses aspectos, a carne de capivara de animais adultos mostra-se com percentual de gordura mais baixo do que as demais carnes convencionais usadas na dieta humana, abatidas em fase de terminação, sendo também mais baixo do que em ovinos abatidos com $15 \mathrm{~kg}$ de peso vivo, descrito por Souza (2001), com média de 1,48 g/100 g no músculo biceps femoris e por Bonagurio (2001), com média superior a $1 \mathrm{~g} / 100 \mathrm{~g}$ de lipídeos totais. Essa quantidade de gordura assemelha-se às médias verificadas em canguru (SINCLAIR e O'DEA, 1990).

TABELA 1 - Média e erro padrão (EP) para teores de umidade, proteína, lipídeos e cinzas e colesterol de capivaras.

\begin{tabular}{|c|c|c|c|c|c|}
\hline \multirow{2}{*}{$\begin{array}{c}\text { Cortes } \\
\text { Comercias }\end{array}$} & $\begin{array}{l}\text { Umidade } \\
\text { (g/100 g) }\end{array}$ & $\begin{array}{l}\text { Lipídios } \\
\text { (g/100 g) }\end{array}$ & $\begin{array}{l}\text { Proteína } \\
\text { (g/100 g) }\end{array}$ & $\begin{array}{c}\text { Cinzas } \\
(\mathrm{g} / \mathbf{1 0 0} \mathrm{g})\end{array}$ & $\begin{array}{l}\text { Colesterol } \\
\text { (mg/100 g) }\end{array}$ \\
\hline & Média \pm EP & Média \pm EP & Média \pm EP & Média \pm EP & Média \pm EP \\
\hline Lombo & $75,09 \pm 0,28^{\mathrm{a}}$ & $0,83 \pm 0,32^{\mathrm{a}}$ & $22,62 \pm 0,42^{\mathrm{a}}$ & $0,92 \pm 0,07^{\mathrm{a}}$ & $33,61 \pm 3,12^{a}$ \\
\hline Carré & $75,07 \pm 0,28^{\mathrm{a}}$ & $1,18 \pm 0,32^{\mathrm{a}}$ & $22,05 \pm 0,42^{\mathrm{a}}$ & $0,83 \pm 0,07^{\mathrm{a}}$ & $31,36 \pm 3,12^{a}$ \\
\hline Peito Fralda & $76,05 \pm 0,28^{\mathrm{b}}$ & $1,25 \pm 0,32^{\mathrm{a}}$ & $21,29 \pm 0,42^{\mathrm{a}}$ & $0,89 \pm 0,07^{\mathrm{a}}$ & $29,99 \pm 3,12^{a}$ \\
\hline Paleta & $76,98 \pm 0,28^{\mathrm{c}}$ & $0,60 \pm 0,32^{\mathrm{a}}$ & $21,48 \pm 0,42^{\mathrm{a}}$ & $0,94 \pm 0,07^{\mathrm{a}}$ & $17,68 \pm 3,12^{b}$ \\
\hline Pernil & $75,84 \pm 0,28^{b}$ & $0,36 \pm 0,32^{\mathrm{a}}$ & $22,45 \pm 0,42^{\mathrm{a}}$ & $0,93 \pm 0,07^{\text {a }}$ & $26,08 \pm 3,12^{a}$ \\
\hline Média Geral & $75,80 \pm 0,28$ & $0,85 \pm 0,32$ & $21,98 \pm 0,42$ & $0,90 \pm 0,07$ & $27,75 \pm 3,12$ \\
\hline
\end{tabular}

Médias seguidas de mesma letra, na coluna, são estatisticamente iguais entre si pelo teste de Scott-Knott ao nível de $5 \%$ de probabilidade $(P<0,05)$. 
Os teores médios de cinzas variaram de 0,83 a 0,94 g/100 g. Em capivaras, Saldanha (2000) encontrou médias de 1,18 g/100 g em pernil e paleta, enquanto Roça et al. (1996) citaram média de 0,9 g/100 g em copa e Jardim (2001) encontrou média de 1,16 g/100 g no músculo LD. Em ovinos, Souza (2001) descreveu variações entre 1,13 e 1,20 g/100 g em ovinos abatidos com 15, 25, 35 e 45kg de peso vivo.

A média de colesterol da paleta $(17,68 \mathrm{mg} / 100 \mathrm{~g})$ foi inferior $(\mathrm{P}<0,05)$ às médias observadas nos demais cortes, que variaram de 26,08 a 33,61mg/100g. Em capivaras, Saldanha (2000) encontrou nos cortes paleta e pernil média de $41 \mathrm{mg} / 100 \mathrm{~g}$, e Jardim (2001) citou média de 44 mg/100 g em músculo LD. Comparando com outras espécies, foram relatados teores mais elevados. Food e Forgerty (1982) encontraram, em carne de canguru, média de 56 mg/100 g. Romanelli (1995), em carne de jacarés-dopantanal, descreveu médias de 85,48 mg/100 g e 63,56 mg/100 g. Bragagnolo e Rodrigues-Amaya (1995) encontraram variações de 50 a 56 mg/100 g em contrafilé, coxãoduro, coxão-mole e peito, sem diferença entre os cortes.
Comparando os dados (composição centesimal) observados no presente estudo com os dados da literatura para espécies convencionais e exóticas (Tabela 2), verifica-se que a carne de capivara apresentou baixa quantidade de gordura e baixa quantidade de colesterol. Essas diferenças podem representar uma ferramenta de marketing para incrementar o consumo de carne de capivara, gerar trabalho e tornar a atividade uma opção rentável para os produtores (SALES et al., 1996). Além disso, essas diferenças no conteúdo de gordura e colesterol entre as carnes de animais selvagens e domésticos são significantes em termos de gordura dietética ingerida e sua relação com o risco de doenças degenerativas crônicas. Pelas pesquisas realizadas por Sinclair e O'Dea (1990), verificou-se que aborígenes australianos alimentados com dieta rica em carne vermelha com baixa porcentagem de gordura (carne de canguru) foi tão efetiva para reduzir o colesterol plasmático quanto dietas vegetarianas ou dietas suplementadas com peixe de água salgada.

TABELA 2 - Médias de umidade, proteína, lipídeos e colesterol em animais exóticos.

\begin{tabular}{|c|c|c|c|c|}
\hline Componente & $\begin{array}{l}\text { Umidade } \\
\text { (\%) }\end{array}$ & $\begin{array}{l}\text { Proteína } \\
\text { (\%) }\end{array}$ & $\begin{array}{l}\text { Lipídeos } \\
\text { (\%) }\end{array}$ & $\begin{array}{l}\text { Colesterol } \\
(\mathrm{mg} / 100 \mathrm{~g})\end{array}$ \\
\hline \multirow{3}{*}{$\begin{array}{l}\text { Avestruz } \\
\text { (ostrich) }\end{array}$} & 75,10 & \multirow{3}{*}{$\begin{array}{c}22,20 \\
\text { Paleari et al. (1998) }\end{array}$} & \multirow{3}{*}{$\begin{array}{cc}1,60 & \text { Paleari } \\
\text { et al. (1998) } 0,90 \\
\text { Sales et al. (1996) }\end{array}$} & \multirow{3}{*}{$\begin{array}{cc}33,80 & \text { Paleari } \\
\text { et al. (1998) 57,00 } \\
\text { Sales et al. (1996) }\end{array}$} \\
\hline & $76,10 \quad$ Sales & & & \\
\hline & et al. (1996) & & & \\
\hline \multirow{2}{*}{$\begin{array}{c}\text { Peru } \\
\text { (turkey) }\end{array}$} & 74,8 & \multirow{2}{*}{$\begin{array}{c}20,4 \\
\text { Paleari et al. (1998) }\end{array}$} & \multirow{2}{*}{$\begin{array}{c}\text { 3,8 } \\
\text { Paleari et al. (1998) }\end{array}$} & \multirow{2}{*}{$\begin{array}{c}36,60 \\
\text { Paleari et al. (1998) }\end{array}$} \\
\hline & Paleari et al. (1998) & & & \\
\hline \multirow{2}{*}{$\begin{array}{l}\text { Ema } \\
\text { (rhea) }\end{array}$} & 73,70 & & \multirow{2}{*}{$\begin{array}{c}1,23 \\
\text { Sales et al. (1999) }\end{array}$} & \multirow{2}{*}{$\begin{array}{c}57,00 \\
\text { Sales et al. (1999) }\end{array}$} \\
\hline & Sales et al. (1999) & & & \\
\hline \multirow{2}{*}{$\begin{array}{l}\text { Camelo } \\
\text { (camel) }\end{array}$} & 74,57 & 20,27 & \multirow{2}{*}{$\begin{array}{c}4,27 \\
\text { Dawood e Alkanhal } \\
(1995) \\
\end{array}$} & \\
\hline & $\begin{array}{c}\text { Dawood e Alkanhal } \\
\text { (1995) }\end{array}$ & $\begin{array}{c}\text { Dawood e Alkanhal } \\
\text { (1995) }\end{array}$ & & \\
\hline \multirow{2}{*}{$\begin{array}{c}\text { Canguru } \\
\text { (kangaroo) }\end{array}$} & & & \multirow{2}{*}{$\begin{array}{c}1,10 \\
\text { Food e Forgerty } \\
\quad(1982)\end{array}$} & \multirow{2}{*}{$\begin{array}{c}56,00 \\
\text { Food e Forgerty } \\
(1982)\end{array}$} \\
\hline & & & & \\
\hline \multirow{2}{*}{$\begin{array}{c}\text { Javali } \\
\text { (wild board) }\end{array}$} & 74,28 & & \multirow{2}{*}{$\begin{array}{c}1,41 \\
\text { Marchiori (2001) }\end{array}$} & \multirow{2}{*}{$\begin{array}{c}\text { 46,42 } \\
\text { Marchiori (2001) }\end{array}$} \\
\hline & Marchiori (2001) & & & \\
\hline
\end{tabular}

Ciênc. agrotec., Lavras, v. 28, n. 6, p. 1344-1351, nov./dez., 2004 


\section{CONCLUSÕES}

Pelos resultados encontrados no presente trabalho, observam-se teores de lipídeos totais $(0,36$ a $1,25 \mathrm{~g} / 100 \mathrm{~g})$ e de colesterol (17,68 a 33,61 mg/100 g) em carne de capivara inferiores aos valores citados na literatura para outras espécies. Com esses dados, verifica-se que a carne de capivara é mais magra do que as demais carnes de espécies de açougue, exóticas e silvestres, e que seu consumo na dieta pode ser favorável à saúde humana.

\section{AGRADECIMENTOS}

Ao CNPq e à FAPEMIG, pela concessão de bolsa de mestrado para as alunas Sandra H. I. Oda e Giulianna Z. Miguel, e à Empresa Pró-Fauna Assessoria e Comércio Ltda., pela doação de amostras e apoio logístico.

\section{REFERÊNCIAS BIBLIOGRÁFICAS}

ALHO, C. J. R. Criação e manejo de capivaras em pequenas propriedades rurais. Brasília: EMBRAPADDT, 1986. 48 p. (Documentos, 13).

ASSOCIATION OF OFFICIAL ANALYTICAL CHEMISTS. Official methods of analysis of the Association of Official Analytical Chemists. 15 ed. Arlington, 1990.

BERLIN, B.; BERLIN, E. A. Etnobiología, subsistencia y nutrición en una sociedad de la selva tropical: los Aguaruna (Jíbaro). In: Salud y nutrición en sociedades nativas: compil. por A. Chirif. CIPA. Lima: [s.n.], 1978. p. 13-47.

BOHAC, C. E. et al. Assessment of methodologies for colorimetric cholesterol assay of meats. Journal of Food Science, Chicago, v. 53, n. 1642, 1988.

BONAGURIO, S. Qualidade da carne de cordeiros Santa Inês puros e mestiços com Texel abatidos com diferentes pesos. 2001. 150 p. Dissertação (Mestrado em Zootecnia) - Universidade Federal de Lavras, Lavras, 2001.

BRAGAGNOLO, N. Fatores que influenciam o nível de colesterol, lipídeos totais e composição de ácidos graxos em camarão e carne. 1997. 123 f. Tese (Doutorado em Ciência de Alimentos) - Universidade de Campinas, Campinas, 1997.
BRAGAGNOLO, N.; RODRIGUEZ-AMAYA, D. B. Teores de colesterol em carne suína e bovina e efeito do cozimento. Ciência e Tecnologia de Alimentos, Campinas, v. 15, n. 1, p. 11-17, 1995.

BRASIL. Ministério da Ciência e Tecnologia. Programa Nacional de Florestas. Decreto n. 3.420, de 20 de abril de 2000. Publicado no D.O.U. de 22.04.2000, Seção I, pág. 2.2 Disponível em: <http://www.mct.gov.br/legis/decretos/ 3420_2000.htm>. Acesso em: 15 jun. 2004.

CRAWFORD, M. A.; CASPERD, M. N.; SINCLAIR, A. J. The long chain metabolites of linoleic and linolenic acids and liver and brain in herbivores and carnivores. Compendium of Biochemic Physiology, [S.l.], n. 54B, p. 395-401, 1976.

DAWOOD, A. A.; ALKANHAL, M. A. Nutrient composition of Najdi-Camel meat. Meat Science, Barking, v. 39, p. 71-78, 1995.

FERREIRA, D. F. Análises estatísticas por meio do Sisvar para Windows versão 4.0. In: REUNIÃO ANUAL DA REGIÃO BRASILEIRA DA SOCIEDADE INTERNACIONAL DE BIOMETRIA, 45., 2000. São Carlos. Anais... São Carlos: Ufscar, 2000. p. 255-258.

FOLCH, J.; LEES, M.; SLOANE-STANLEY, G. H. A simple method for the isolation and purification of total lipids from animal tissue. Journal of Biological Chemistry, Baltimore, n. 226, p. 497-509, 1957.

FOOD, G. L.; FOGERTY, A. C. The fatty acids of kangaroo and wallabi meat. CSIRO Food Research, Melbourne, v. 42, n. 1, p. 57-60, Jan./Mar. 1982.

FORREST, J. C. et al. Fundamentos de ciência de la carne. Zaragoza: Acribia, 1979. 364 p.

GAONA, J. L. T. La carne del chigüiro como alimento. Temas de Orientacion Agropecuaria, Bogotá, v. 9, n. 99, p. 69-75, 1987.

GAVIRIA, A. La fauna silvestre y su aprovechamiento por las comunidades nativas del río Pichis. In: SEMINARIO SOBRE PROYECTOS DE INVESTIGACIÓN ECOLÓGICA PARA EL MANEJO DE LOS RECURSOS NATURALES RENOVABLES DEL BOSQUE TROPICAL HÚMEDO, 1980, Iquitos. Annales... Iquitos: Ministerio de Agricultura/ ORDELORETO, 1980. p. 196-202. 
HERRERA, E. A. Comportamiento, conservación y manejo de fauna silvestre: el caso del capibara en Venezuela. Etología, [S.l.], v. 7, p. 41-46, 1999.

INSTITUTO BRASILEIRO DO MEIO AMBIENTE E DOS RECURSOS NATURAIS RENOVÁVEIS. Portaria n. 118/97, de 15.10.97. Regulamentação da criação de animais da fauna silvestre brasileira com fins econômicos e industriais. Disponível em: <http://www.ibamapr. hpg.ig.com.br/Prt118-97.htm>. Acesso em: 15 jun. 2004.

JARDIM, N. S. Sexo e diferentes pesos ao abate na qualidade da carne de capivara (Hydrochaeris hydrochaeris L. 1766). 2001. 119 p. Dissertação (Mestrado em Ciência de Alimentos) - Universidade Federal de Lavras, Lavras, 2001.

JARDIM, N. S. et al. Teor lipídico e perfil de ácidos graxos da carne de capivara (hydrochaeris hydrochaeris). Ciência e Agrotecnologia, Lavras, v. 27, n. 3, p. 651657, maio/jun. 2003.

MARCHIORI, A. F. Composição e propriedades físico-químicas da carne de javali e suíno comercial. 2001. 71 f. Dissertação (Mestrado em Tecnologia de Alimentos) - Universidade de Campinas, Campinas, 2001.

MOREIRA, T. R.; CLARKE, J. R.; MACDONALD, D. W. The testis of capybaras (Hydrochaeris hydrochaeris). Journal of Mammalogy, [S.l.], v. 78, p. 1096-1100, 1997.

NAUGHTON, J. M.; O'DEA, K.; SINCLAIR, A. J. Animal foods in tradicional aboriginal diets: polyunsaturated and low in fat. Lipids, Champaign, v. 21, p. 684-690, 1986.

OJASTI, J. Estudio Biológico del chigüire o capibara. Caracas: FONAIAP, 1973.

PALEARI, M. A. et al. Ostrich meat: physico-chemical characteristcs and comparison with turkey and bovine meat. Meat Science, Barking, v. 53, n. 3/4, p. 205-210, 1998.

PARDI, M. C. et al. Ciência, higiene e tecnologia da carne: tecnologia da sua obtenção e transformação. Goiânia: Universidade de Goiás, 1993. v. 1, 586 p.
ROÇA, R. O. et al. Desenvolvimento de produtos curados e defumados com carne de capivara (Hydrochoerus hydrochaeris). In: CONGRESSO BRASILEIRO DE CIÊNCIA E TECNOLOGIA DE ALIMENTOS, 15., 1996, Poços de Caldas. Resumos... Poços de Caldas: SBCTA, 1996. p. 45.

ROMANELLI, P. F. Propriedades tecnológicas da carne de jacaré-do-pantanal (Caiman crocodilus yacare). 1995. Tese (Doutorado em Engenharia de Alimentos) - Universidade de Campinas, Campinas, 1995.

ROSTAGNO, H. S. et al. Composição de alimentos e exigências nutricionais de aves e suínos: tabelas brasileiras. Viçosa: UFV, 2000. 141 p.

SALDANHA, T. Determinação da composição centesimal nos diferentes cortes da carne de capivara (Hydrochoerus hydrochaeris). 2000. $105 \mathrm{f}$. Dissertação (Mestrado) - Universidade Federal Rural do Rio de Janeiro, Rio de Janeiro, 2000.

SALES, J.; MORAIS, D.; KRUGER, M. Fat content, caloric value, cholesterol content, and fatty acid composition of raw and cookie ostrich meat. Journal of food Composition Analysis, [S.l.], v. 9, n. 10, p. 85-89, 1996.

SALES, J. et al. Cholesterol content and fatty acid composition of rhea meat. Meat Science, Barking, v. 53, p. 73-75, 1999.

SANTOS, C. L. Estudo do desempenho, das características da carcaça e do crescimento alométrico de cordeiros das raças Santa Inês e Bergamácia. 1999. 143 p. Dissertação (Mestrado em Zootecnia) - Universidade Federal de Lavras, Lavras, 1999.

SCOTT, A. J.; KNOTT, M. A. Cluster analysis method for grouping means in the analysis of variance. Biometrics, Washington, v. 30, n. 3, p. 507-512, Sept. 1994.

SINCLAIR, A. J.; O’DEA, K. Fats in Human diets through history: is the western diet out of step? In: WOOD, J. D.; FISHER, A. V. Reducing fat in meat animals. London: Elsevier, 1990. p. 1-47.

SINCLAIR, A. J.; SLATTERY, W. J.; O'DEA, K. The analysis of poliunsaturated fatty acids in meat by capillary gas-liquid chromatography. Journal Science Food Agriculture, London, v. 33, n. 8, p. 771-776, Aug. 1982. 
SOUZA, X. R. Efeitos de grupo genético, sexo e peso ao abate na qualidade de carne de cordeiros em crescimento. 2001. 116 p. Dissertação (Mestrado em Ciência dos Alimentos) - Universidade Federal de Lavras, Lavras, 2001.

SOUZA, X. R. et al. Composição centesimal do músculo Biceps femoris de cordeiros em crescimento. Ciência e Agrotecnologia, Lavras, p. 1507-1513, dez. 2002.
TARLEY, C. R. T. et al. Proteína, colesterol e ácidos graxos ômega-3 e ômega-6 em músculo Longissimus dorsi de caprinos cruza Saanen. In: SIMPÓSIO LATINO AMERICANO DE CIÊNCIA DE ALIMENTOS, 3., 1999, Campinas. Anais... Campinas: UNICAMP, 1999.

WOOD, J. D. Consequences for meat quality of reducing carcass fatness. In: WOOD, J. D.; FISHER, A. $\mathrm{V}$. Reducing fat in meat animals. London: Elsevier, 1990. p. 344-389. 